\title{
Pandemic Risk and Standpoint Epistemology: A Matter of Solidarity
}

\author{
Katrien Schaubroeck ${ }^{1}$ D $\cdot$ Kristien Hens $^{1}$ (D)
}

Accepted: 12 October 2021 / Published online: 25 October 2021

(c) The Author(s), under exclusive licence to Springer Science+Business Media, LLC, part of Springer Nature 2021

\begin{abstract}
Current and past pandemics have several aspects in common. It is expected that all members of society contribute to beat it. But it is also clear that the risks associated with the pandemic are different for different groups. This makes that appeals to solidarity based on technocratic risk calculations are only partially successful. Objective 'risks of transmission' may, for example, be trumped by risks of letting down people in need of help or by missing out certain opportunities in life. In this paper we argue that a rapprochement of the insights of standpoint epistemology with pandemic science and pandemic policy making may be an important step toward making pandemic science more accurate and pandemic calls for solidarity more effective.
\end{abstract}

Keywords Standpoint epistemology $\cdot$ Risk $\cdot$ Inclusive science $\cdot$ Inclusive democracy $\cdot$ Pandemic

\section{Introduction: Standpoint Epistemology}

As has become apparent during the COVID-19 pandemic and previous pandemics, solidarity is a key element of beating the virus. In order to alleviate and in the end cancel pandemic risks, all community members are asked to give up aspects of normal life and refrain from doing certain activities. However, this call for solidarity is challenged by the fact that the risks associated with pandemics are not easily quantifiable and affect different people and different groups in different ways. This is made even more complex by the fact that such risks cannot be grasped in a technocratic and objectifiable way alone. Risks are personal in at least two ways. They are specific to circumstances and they are defined by reference to values. In this paper, we argue that in order for pandemic science to fully grasp and weigh the risks at hand

Katrien Schaubroeck

Katrien.Schaubroeck@uantwerpen.be

1 Philosophy Department, University of Antwerp, Antwerp, Belgium 
and in order for appeals to the duty of solidarity to actually work, we must take to heart the insights of standpoint epistemology.

Standpoint epistemology emerged from the social justice movements of the 1970's. They stated that reliable research that wants to guide policy should start from questions arising from the everyday lives of members of groups that were oppressed or discriminated against. Standpoint epistemology starts from the premise that scientific practice is always situated: scientific knowledge is generated by scientists from their specific context and situation. Until recently, it is argued, scientific practice was almost exclusively done by white, male, middle-class persons, making it only weakly objective. Feminist standpoint epistemologists such as Sandra Harding argue that, as science claims to understand reality as a whole and wants to produce maximally reliable results, a strong objective science should incorporate viewpoints and experiences from those whose context and situatedness are different, for example because they are part of a marginalised group. Looking back at almost 50 years of standpoint epistemology, Harding writes: "Through the efforts of marginalised members of the sciences, as well as of many non-marginalised scientists who immediately recognised the importance of the issue, this [i.e. incorporating the standpoints of marginalised groups] rather quickly became the strong objectivity standard for good research across virtually all such sciences". She is rather optimistic about the scientific treatment of the COVID-19 pandemic: "The sciences today realise that if they want to understand how COVID-19 and the associated economic crisis actually work, not to mention climate change, they have to start off their research from the daily lives of the least advantaged peoples" [10]. This optimism may be warranted in local contexts. However, globally speaking we do not think that strong objectivity has become 'the guiding standard in virtually all sciences'. Pandemic science would have looked different if that had been the case. We will defend what changes are needed in "Standpoint Epistemology and Inclusive Science" section. The starting point for this article is that just as the social justice movements in the 70s did, the pandemic crisis of 2020-2021 shows that we are in need of a new wave of standpoint theory.

Harding's optimism reflects the reality that philosophical discussions on standpoint epistemology have indeed been ongoing for some decades now within academia. Perhaps as a result of that stakeholder engagement is considered good scientific practice. The risk-and-emotions-theory of Sabine Roeser is a good example here. Relying on a well-established meta-ethical idea that emotions give access to evaluative knowledge, Roeser urges policy makers to not disregard emotions as irrational and she defends a participatory approach to democratic policy-making as a middle ground between technocracy and populism [19]. Also the popularity of Citizen Science projects that engage citizens in gathering scientific data, testify to the decentralisation of scientific projects. Nowadays, funding agencies expect researchers to engage stakeholders from the start. Although we applaud these evolutions, we believe that more is needed in order to achieve Harding's strong objectivity. For one, taking standpoint epistemology seriously is not only about incorporating values and desires of stakeholders in research. It is about incorporating and acknowledging the situatedness of research, and acknowledging the limitations of one's own perspective. Secondly, and related to this, standpoint epistemology is not only 
concerned with incorporating as many standpoints as possible, but more importantly with incorporating the specific viewpoints of those who are the victims of a certain system or certain practice. They have privileged knowledge of where a system or a practice fails. Yet they are not always included in stakeholder engagement or citizen science projects. To the contrary, current practices in stakeholder engagement struggle with the fact that those stakeholders willing to participate in scientific practices, are already in a somewhat privileged position. The COVID-19 pandemic has demonstrated that those who may have privileged access to knowledge about the impact of the pandemic, are those not typically involved in stakeholder engagement. Think about the very old, underage people, people with intellectual disabilities, people living in poverty.

We argue that science and public debate that are enriched with methods from standpoint epistemology yield better science and better public debate because they give special credits to the knowledge acquired by people in oppressed circumstances. To explain how pandemic science could benefit from greater inclusivity we will focus on the concept of risk. Pandemic crises, especially when caused by a new pathogen, are defined by uncertainty and unpredictability. The need to assess risks makes it all the more important to acknowledge the limits of each particular standpoint and to collect as many standpoints as possible. In what follows, we shall illustrate how standpoint epistemology can contribute to solving fundamental problems in the philosophy of risk ("Conceptualising Risk: Objective, Subjective and Value-Laden" section) and the philosophy of science and science communication ("Standpoint Epistemology and Inclusive Science" section). These problems are not specific to pandemic science but the pandemic makes the problems all the more urgent. What is at stake is, as we will show in "The Challenges of Pandemic Solidarity" section with examples from the Belgian context, solidarity itself.

\section{The Challenges of Pandemic Solidarity}

At the height of the pandemic, the call for solidarity is loud and clear. Politicians tell citizens that 'we are in it together'. And true enough, if we ever want to escape the situation we are in, all of us have to contribute to beating the virus, by restricting physical contact and by getting vaccinated. So on the one hand the call for solidarity is legitimate. But on the other hand we see solidarity challenged in many way which put pressure on the idea that 'we are in it together'. We will distinguish three challenges to solidarity during the pandemic after setting out its meaning.

Léon Bourgeois has described solidarity as a natural and practical middle ground between individualism and collectivism [3]. It is natural because it arises organically from the fact that all individuals are associated in society, to their benefit. In return, individuals also have an obligation towards society. Barbara Prainsack and Alena Buyx have described solidarity as "enacted commitments to accept costs to assist others with whom a person or persons recognise similarity in a relevant respect" [18]. Surely being 'in it together' in a pandemic should be a paradigmatic situation in which solidarity is high, and where it can be leveraged as a way to fight the pandemic. Still, the ongoing pandemic has polarised the debates on what is the extent 
of solidarity. To whom should we show solidarity? That this question provoked divisive, hard and ugly discussions in society is precisely what was to be expected, says Prainsack in a recent article [17]. Following up on what Prainsack and Buyx wrote in 2011 [18], she repeats the argument: "Because pandemics come about in a relatively short period of time where people have very different risks and stakes, the possibilities of mobilising solidarity to support public health measures are limited... If governments and public authorities call upon people to do something costlysuch as staying at home, home-schooling their children, or accepting losses of income or even their jobs for the sake of protecting a few-we argued, this is likely to raise resistance in the population" [17]. And they proved right. They argue that the timespan of a pandemic is not long enough for people to move through stages of needs (for example to become old and needy). This hampers the recognition of similarity which is essential to stimulate solidarity. This is the first challenge.

Additionally we think that there is an additional factor that might explain the resistance against calls for solidarity. At the time of writing this article, there are severe floods in the East of Belgium and the West of Germany. The images of families sitting on roofs waiting for rescue helicopters cause a wave of solidarity throughout the country. People do realise that it could just as well have been them, sitting on the roofs watching the water destroy their life work. In the case of the current pandemic, the virus affects people differently. Many people correctly assume that they will not be affected by the pandemic as much as the people for whom they have to sacrifice certain aspects of their lives [13]. As soon as it became apparent that the strong and healthy, not obese, not smoking, etc.... are less likely to end up in hospital after an infection, the logic of 'us versus them' came naturally to some. In a way that logic is based on what is scientifically known about the virus. ${ }^{1}$ It thus constitutes a second challenge to solidarity.

At the same time, we should note that 'us versus them' is a very shortsighted logic. Indeed, the chances of dying from COVID-19 are aligned along distinctions between 'us', the wealthy and healthy, versus 'them', the poor and less healthy. But whether one is born in a poor family, with bad housing conditions, low-payed jobs, no access to health care etc.... is as well a matter of pure luck. Every human being's parents could have lost their jobs, everyone could have been born in a country that goes to war and forces their citizens to flee etc.... But being human is not strong enough a similarity to invoke solidarity, that has been argued by many before $[20,12]$. And therefore the us-them-logic that has thwarted feelings of solidarity over the last year was to be expected. This reality questions the prediction offered by West-Oram and Buyx in their 2017-paper on global health solidarity [22]. They argued that global crises will shift the perception of who is vulnerable to exogenous health threats such as infectious diseases and environmental pollution. Globalization, climate change, antimicrobial resistance would redraw the lines between 'us' in western societies who have nothing to fear and 'them' in the global South who are

\footnotetext{
1 This is why calling the pandemic 'a natural disaster' is misleading. As Pascoe and Stripling have explained, the narrative of 'a disaster of public health care' fits the scientific data much better, and would also invoke more fruitful ethical discussions [13].
} 
vulnerable because deprived. Insofar as West-Oram and Buyx mean that the global North will be confronted with flooding and extreme weather conditions just as much as the global South, they are correct that the line between 'us' and 'them' will no longer map onto a geographical separation. But as the recent pandemic has shown, the lines are likely to be redrawn within western societies themselves. Global health crises like the COVID-19 crisis have sharpened rather than mitigated the differences between a privileged and a deprived group of people. The shift in perception that Buyx and West-Oram predict might not lead to a global solidarity, we fear, as long as the longstanding inequities amongst 'us' are not addressed. So that is the third obstacle to solidarity.

In prepandemic times, overall, many people would agree that solidarity is a good thing, and that for example vaccinations are important to protect not only oneself but also other people. In solidarity we acknowledge the potential vulnerability of each of us. But in pandemic times, solidarity is put under pressure and sometimes even evaporates. Remember that solidarity arises from a recognition of similarity. This distinguishes it from the motive of charity. Charity arises from an acknowledgment of difference: the ones who receive charity are considered vulnerable, unlike the one who show charity. Because pandemic policy asks for serious efforts, people are less likely to acknowledge that they are vulnerable when they do not feel vulnerable at all. Given the higher mortality rate among groups that live in the margins of society, we might wonder whether there has ever been any solidarity at all. In that respect the pandemic crisis works as a mirror, holding the fault lines in our society in our face. The pandemic reveals what has always been the case: a very complicated relation between risk, vulnerability, and solidarity to such an extent that it may become impossible to provide any guideline as to whom should be solidary with whom. To illustrate this complicated relation, we can look at two arguments or cases that have been used in the public discourse regarding lockdowns and stay-at-home orders.

The first argument is an (un)fairness argument. The gist of this argument is that it is unfair to ask children and young people who overall experience only mild symptoms from an infection by COVID-19 to give up their right of a social life and of an education in order to protect older people and people with underlying health conditions. The solution is then that all those who run higher risks when infected should stay at home and practice social distancing, while the rest of us can lead a less restricted life. Such 'reverse lockdown' was for example argued for by a group of Belgian academics in August 2020 [11]. For those who argue in this way, this solution is clean, just and rationally ethical: let those who run the most risk protect themselves. Remark that this argument is contrary to the principle of solidarity as we would assume it in prepandemic times: that burdens of the vulnerable minority are somewhat shared in the population, in the assumption that we are all potentially vulnerable. Moreover, there are probably several implementational flaws in this reasoning: complete segregation of those who are potentially severely affected by COVID-19 infection and those who are not is impossible, even if we would consider this ethical. But there is also something problematic on another level. We may assume that it is risky for children to miss out on school or for first year university students to miss out on social activities and in person classes on campus. But it may also be risky for them, in a different sense, to miss out on contact with certain family members for a prolonged time. We do not know what it 
means for social dynamics if one group in the population has to give up everything and the other group nothing. How can we weigh these different dimensions of risk against one another? For many people, it may be straightforward that the majority should not sacrifice everything to accommodate a minority. For example, although for a minority of children the combination of online classes with live classes has proven to be beneficial, this argument does not seem to hold much weight against the arguments that it is overall better to keep schools open for as long as possible. But, as we will argue below, understanding the position of different stakeholders, also those belonging to a minority, may open up new perspectives on how to evaluate the relation between risks and duty to solidarity. It can point a way to a society that is more inclusive. The point that standpoint theory makes is even stronger: members of a minority group, living in a system that does not suit their preferences and needs very well, have privileged access to knowledge about how to improve the system. They are important sources of information for our sciences and science-based society.

A second example is therefore related to inclusion. It is inspired by the remarks of some people with disabilities regarding accessibility (see for example [23]). In prepandemic times, accommodations disabled persons needed in order to study or work properly were often denied. For example, it was impossible to attend courses at universities online and telecommuting was not allowed, even if it was technically possible. With the pandemic, those accommodations that were not considered possible for them, suddenly became available from the moment able-bodied people needed them. In a certain way, this allowed disabled persons to participate in activities that were previously inaccessible. Several months in the pandemic, many people are getting tired of online classes and work from home and are hoping for a world where everything is 'back to normal'. Disabled persons have voiced fears that this idea of back to normal also implies that there will again be less opportunities to participate. Several risks are at stake here. The risk that people who can participate in live classes and onsite work are deprived of social contacts should online classes and work from home remain the norm for a longer period of time. But there is also the harm that is done when disabled persons are deprived of social contacts and the opportunities should the majority decide that going back to the prepandemic situation is the best.

Calls to solidarity are at least partially calls to alleviate harms for vulnerable persons or to share burdens. In the context of a pandemic, it is taken for granted that scientific knowledge about transmission risks and fatality risks can at least do some of the work to increase solidarity. But the variety of pandemic risks and harms, however, cannot very well be reduced to transmission and fatality risks: we cannot merely calculate relevant risks using methods such as calculations of transmission risks. Moreover, appreciating these risks cannot be done independently of context, they cannot solely be assessed by technocratic methods. In what follows, we describe some approaches to risk in philosophical and sociological literature, and the problems in risk studies revealed by the pandemic. 


\section{Conceptualising Risk: Objective, Subjective and Value-Laden}

The lemma on 'risk' in the Stanford Encyclopedia of Philosophy defines several different meanings of the term risk in everyday language [7]. Risk may refer to an unwanted event (a harm) that may or may not occur. It may also refer to the cause of such an unwanted event, or the probability that an unwanted event may or may not occur. Or, more technical, the statistical expectation value of an unwanted event which may or may not occur. The standard technical definition of risk that is adopted in many disciplines, makes a distinction between risk and uncertainty: risk is then the fact that a decision is made under conditions of known probabilities. If these probabilities are unknown, we should talk about uncertainty rather than risk. In what follows, we shall use the term 'risk' as an umbrella term both for causes and probabilities, and we shall not sharply draw the distinction between risks and uncertainties. For one, we may wonder if, when confronted with a new pathogen such as COVID-19, all risk may in fact become uncertainties, given the many unknowns of what variants may still arise, or what the long term effects of an infection are. In this respect, the difference between risk and uncertainty may become too artificial. Moreover, we want to focus on what we believe is a relevant, but underappreciated aspect of risk, harm and uncertainty: the fact that it always has a normative component. Indeed, philosophers have criticised technical definitions of risk for being too limited and not covering all relevant aspects of risk assessment like the normative aspect. Therefore, philosophy of risk often works with the non-technical concept of risk as a state of affairs in which an undesirable event may or may not occur. However, this informal understanding still remains silent about conceptual problems related to what is meant with 'undesirable', to which we will turn next.

Indeed, a large part of the philosophical literature on risk refers to risk in the informal sense of a state of affairs in which an undesirable event may or may not occur. Two elements in this conception of risk are important. First, when there is risk, there is lack of knowledge about what will be the case. And second, when there is risk, there is the possibility that something undesirable will take place. Calling a particular envisioned future situation a risk thus implies a value judgment: it would be bad if that situation came about. For example, if a specific prenatal test is advertised to predict the risk of the fetus to have trisomy- 21 with $99.5 \%$ accuracy' this may refer to actual numbers of prediction. However, by using the word 'risk', it is also implied that this would be an undesired outcome, which is a normative statement. Even if the involved value is widely shared, a value judgment always retains an element of subjectivity, be it intersubjectivity: it is a judgment at a particular time and place made by particular people on what they find valuable. Concealing this aspect by talking about 'objective risk' is tempting, and it may explain why in acute emergency situations, policy makers by default revert to a technoscience approach: what counts as a risk is approached as objectifiable to population numbers suggesting transmission rates, projected mortality rates etc.. It might seem only logical that in situations that affect a great many people, we 'let the data speak', and use 'objective cost-benefit analysis' to plot the best course. Given the speed with which 
the situation escalated, and under which amount of uncertainty decisions had to be made to mitigate the spread of the virus, these decisions are understandable.

Nevertheless, now that we are several months along, the limits of such an approach become apparent. Obviously, reducing mortality figures and protecting physical health are values that guide the decisions made during a pandemic. These values were driving the risk-talk, and are not contested as values in themselves. But when there are trade-offs to be made, it becomes clear that other values may define which risks are risky enough to be included in calculations and which are not. As the months go by some commentators have put forward economical stability as a value too costly to risk. But surely also mental health and social cohesion are values to be considered.Given the right number of data, it may be possible to calculate transmission risks in themselves. But as the reference to economic, mental health and social risks suffices to show, there is a trade-off between so-called objective risks, which is often left implicit. As these different types of risks cannot be merely compared or weighed, deciding which ones are more important is by definition a normative endeavour.

Moreover, as Ulrich Beck has argued in the context of pollution in his seminal work Risk Society, specifically globalised risks become incalculable, and the attempt to control a risk may produce other risks [1]. Risks are no longer merely probabilities that we can calculate and on the basis of what we can take decisions: the actual present and future risks are uncertain. This uncertainty is not only an effect of the complexity of the problem but is inherent to pandemic science making. For starters, scientists decide what to call a pandemic, and what not, thereby running epistemic risks which we will cover in "Standpoint Epistemology and Inclusive Science" section. Also the question of what risks should be prioritized, or what risks are relevant becomes almost impossible to solve. For example, do we bring into the equation the risk that we become infected with COVID-19, that we are hospitalized or that we die from it? Different countries made different decisions. New-Zealand chose to go hard and go early. Most European countries, including Belgium, were guided by limits of their ICUcapacity. In the beginning of the pandemic, what was to be avoided was the collapse of the health care system, due to a potential steep rise in hospitalizations. Now that more and more people are vaccinated, this risk has been lessened. At the same time, more data regarding the long term effect of even a 'mild' covid infection become available. Whether the risk of long term effects is considered important enough to prolongue measures to prevent spreading of the virus is an ongoing discussion. In any case, what the current pandemic has taught us is that it has become unclear what 'follow the science' actually means. We will come back to this point in the next section when we focus on the many hazards and risks involved in science and scientific policy advice. Science as it stands may just not have sufficient information to objectify what risks we are dealing with.

Still, a (scientific) understanding of all relevant risks we face may be a first prerequisite for a call for solidarity to work. What the pandemic has made abundantly clear is that a rich concept of solidarity, which is not reducible to a tyranny of the majority or a tyranny of the minority/vulnerable, requires a reappraisal of the life, context and challenges of different groups of individuals. In 
fact, a mature scientific approach is not solely technocratic: it engages with different realities of different stakeholders. As such, it deals with risks in a way that is both imaginative and objective. As we argue in the next section, this means that it should take standpoint epistemology seriously.

\section{Standpoint Epistemology and Inclusive Science}

The need for more inclusive science-making as well as policy-making is evident if we look at past dealings with epidemics of highly infectious viruses. For example, thanks to feminist journalists' reports about the Zika and Ebola outbreaks, the current Secretary-General of the UN Antonio Guterres acknowledges that pandemics hit men and women differently. But this insight is still not pervasive in scientific practices (f.e. not all available data about COVID-19-cases and deaths are sex-disaggregated) nor in policy making (f.e. that complete lockdowns increase the cases of partner violence and child abuse, was not taken into account nor prepared for during the first lockdown). When feminist activists (f.e. Natacha Waldmann in Belgium, Caroline Criado Perez in the UK) called for a better gender balance in advisory boards, they were ridiculed by some. But in fact their plea is backed up by long established claims from standpoint epistemology [14].

As we described before, standpoint epistemology starts from the all too evident fact that all knowledge is situated. Every piece of knowledge is gathered, possessed or communicated in a specific context by someone with a specific body, a particular cognitive style, personal interests and hence values, etcetera. Feminist epistemologists have done much to dismantle the myth of the neutral standpoint of science [8,9]. Science as we know it is done by scientists, and no human being is as immaterial as the objective 'view from nowhere' suggests. This is no reason to mistrust science. All it means is that science needs to be put into perspective and the scientific community as well as the scientific data should be made as inclusive as possible. The pandemic has shown the urgency of this plea because policy design in many (though by no means all) countries followed the science. Given scientists' impact on society especially during a pandemic we believe that it is imperative to include as many different social positions as possible, and to realise that different social situations lead to different experiences and hence different epistemic perspectives. That may broaden the understanding of the scope of risks entailed by the pandemic.

Especially in the context of democratic policy-making it would be unjust to neglect the truths that only socially disadvantaged groups have access to. It would constitute a specific form of injustice: epistemic injustice. The phenomenon of epistemic injustice (that is, the injustice being done to people when they are not respected in their capacity as knowers) [5] is well documented and researched. We believe that the concept is applicable to how current crisis policy making is done, as it does not sufficiently take seriously the testimony of many social groups that suffer badly from the decisions made. We will give three examples of failures of pandemic policy due to epistemic injustice. These examples, from a Belgian context, underscore the need for science to remedy these injustices whenever they are asked for 
policy advice. In some instances science succeeds in helping to overcome the injustice, but in other instances science is itself part of the problem as we will explain with the help of philosophers of science and science communication.

Some social groups that suffer from the lockdown get media attention or spokespersons, like the students, the hairdressers and the restaurant owners. But other voices, like those of unemployed people in apartment towers with no green space are unheard. Their 'lockdown' does not come with an extra economic cost, and they are hardly represented in advocacy groups, so there seems no direct reason why the media should pick up their testimonies. Yet an inclusive democracy should take their interests into account: they are citizens like everyone else, and they suffer badly from the decisions to close down playgrounds and skate parks, to close down schools, to forbid religious ceremonies, to close food banks and other volunteering projects. They are asked, like everyone else, to be solidary, but their burdens are a lot heavier than those of families living in lofty houses with a garden, stable internet connection, enough to eat and not dependent on any social support that fell out during lockdown. The restraining order to stay home revealed a painful political unawareness of the existence of homeless people. It became apparent that the default citizen for whom Belgian policy is made, is the middle class family of four. The scientific panel that consulted the Belgian government, and that almost exclusively consisted of scientists from the medical sciences, did not correct for this bias.

A second group of overlooked citizens is the group of people who lost a loved one during the pandemic. During the second lockdown (November 2020-February 2021) the Belgian government ordered that funerals could be attended by maximum 15 people. While from a policy standpoint it might seem unfortunate yet reasonable to restrict in terms of an absolute number, from the standpoint of a mourning family this is almost unbearable. They could not assist their loved ones in their last hours (because of safety measures no visitors were allowed in hospitals). They could not not see the deceased (because it was thought that the virus could be transmitted up till $24 \mathrm{~h}$ after the death of an infected person). Moreover, they also had to choose who could attend the funeral. For large families this choice may be excruciating. A reasonable alternative was to limit the attendance to first line family members only, or the option to make orders relative to the size of the church or crematorium (as was done with the retail stores and the museums from December onwards). The funeral industries in Belgium, however, are not organized enough to lobby and mourning people lack the energy to fight a policy. Consequently, at least in Belgium, there was very little attention for the difficult situation in which people had to mourn if we compare this to how much media coverage there was of depressed students and unruly coiffures. The funeral industries are only weakly tied to scientific domains and academic knowledge production. There is no overarching 'science' of funeral industries, there is no official educational school that could negotiate with the government. There are also very few experts who could formulate recommendations to the government and point them effectively to scientific data about long term impacts of complicated grief on both personal health and social cohesion. All these facts explain why the needs of people in a very vulnerable stage of their lives were not heard. 
Another social group in Belgium that was unheard for a long time but has spoken up consists of religious communities. When the Belgian government decided to keep garden centres and book stores open during the second lockdown of November 2020, and subsequently to reopen retail stores like IKEA, swimming pools and musea after four weeks, but at the same time decided to forbid worship services in churches, synagogues and mosques for much longer, many religious people felt discriminated against. It seemed to some that the government had put the interests of middle-class secularised privileged people with gardens before the spiritual needs of citizens who in Belgium mostly belong to minority groups (like the elderly or the citizens with a migration background). That their interests, which do not need to constitute greater risks of transmission than those of consumers, were not taken into account could very well be interpreted as an epistemic injustice. 'Objective' risks were allocated to one context (church going) and minimised in the context of consumption. Arguably economic interests and not just chances of transmission influenced what risk was acceptable. Jewish communities went to court and won their case. On December 8 the Council of State judged the total prohibition on worshipping as disproportionate and ordered the Belgian government to make exceptions to the general lockdown as it had done for retail stores. And indeed from December 13 onwards the same safety measure were applicable to places of worship as to museums, swimming pools and retail settings. In this specific Belgian case the scientific results backed up the court's ruling. Indeed, the vast majority of transmission happens in indoor places such as gyms, restaurants and places of worship. However, several studies also predict that restricting the maximum occupancy at these places is more effective than uniformly reducing mobility to these places [4]. Of course scientific insights have grown over the months, and while it is generally accepted now that human behaviour rather than the setting itself is the cause of transmission, one might excuse the Belgian government for wanting to play safe back in November 2020. Yet it is remarkable that until the religious communities raised their voice in the public debate, went to court and won their case, they were not heard. Arguably a democratic government should check for blind spots and biases in their policies. A liberal democracy should care for and inquire after the rights and interests of all citizens regardless of how vocal they are.

Every country has their own examples (in some countries, worshippers will not be considered to belong to a social minority as they do in Belgium). But the feature that we want to draw attention to is common to all examples: groups that are prior to the pandemic already in a disadvantaged socio-political position were hit hardest by the measures. This bolsters a claim made by many others that the pandemic as a social phenomenon was man-made and not a natural disaster [13]. The solution to the pandemic is therefore not purely a matter of revealing in ever more detail the laws of nature. The solution also lies in making politics, as well as science more inclusive by taking the message of standpoint epistemology to heart. The three examples above illustrated a lack of inclusivity in policy making. But as we will go on to show also science would improve if more scientists were more self-conscious of their social position and how that affects and possibly limits their epistemic choices. Refusing to do this may not only lead to epistemic injustice but also to, first, bad science and, second, suboptimal science advice to politics. We will argue 
for both claims separately by drawing on work from resp. Biddle and Kukla [2] and Pielke [15]. Philosophers of science Biddle and Kukla argue that the determination of what counts as a health risk is itself a risky business because scientists have to make epistemic choices and are liable to epistemic risks. Pielke shows that science communication involves taking moral risks that scientists should be well aware of. We will spell out their argumentation and its relevance to the issue of pandemic risk. In the end what is at issue is solidarity as hindered or helped by science.

When designing and conducting their research scientists run epistemic risks. That is well-known and unavoidable, given the high complexity of their research [2]. A famous form of epistemic risk is inductive risk: the risk that one draws the wrong empirical hypothesis from statistical evidence. There are other risks, like the risk involved in wrongly characterising the data itself. Think of how to interpret slides of affected lungs: is there a tumor or not? In this case, as Biddle and Kukla put it, "the question is not how much evidence do we need in order to accept or reject a hypothesis, but rather: What is the evidence in the first place?". The form of epistemic risk, coined by Biddle and Kukla as 'phronetic risks' are especially relevant to our argument. Phronetic risks are defined as "epistemic risks that arise during the course of activities that are preconditions for or parts of empirical (inductive or abductive) reasoning, insofar as these are risks that need to be managed and balanced in light of values and interests". For example how scientists operationalise disease concepts comes with phronetic risks. As the definition concedes, setting criteria for inclusion in a category that will be the topic for empirical reasoning is a necessary precondition of empirical research. So it is an unavoidable step. But, as many philosophers of science have already pointed out [6], there is a degree of uncertainty in calling a certain condition an illness (Biddle and Kukla offer the examples of 'erectile dysfunction', 'depression' and 'infertility'). That risk is not due to the hazards of statistical inference, and is therefore better detected as a distinctive kind of risk that is managed in light of values and interests. Problems arise when the 'phronetic' nature of the risk taken is not acknowledged. Biddle and Kukla's goal to make us recognise the variety and pervasiveness of epistemic risks in order to allow for a better understanding of the role of values and interests in science is motivated by an insight at least as old as Michel Foucault: "The social organisation of epistemic activity shapes what knowledge is produced, how it is produced, and what is ignored". It is important to stress that there is no suggestion of a central, let alone evil, mastermind. It is enough that biases, preferences, negotiations put micropressure on every part of the science production chain to push science in a certain direction regardless of one individual's intentions.

The scientific research sparked by COVID-19 is unquestionably marked by many epistemic risks, some of them to be located at the conceptual stage of categorising and thus taking the form of a phronetic risk. Consider the phenomenon of long COVID. Initial research and treatment was aimed at the illness called COVID-19. Symptoms like fatigue, chest pain, depression, coughing, loss of olfactory that could last for 6 months or longer were not seen as part of COVID-19, and hence were not on clinicians' or scientists' radar for a long time.

Long COVID became the informal name to describe the effects of COVID-19 that continue for weeks or months beyond the initial illness. In December 2020 The 
Lancet announced that "the WHO is planning to update its guidance and resources for clinical management of COVID-19 to include long COVID" [21]. That it took the WHO and other organisations many months to understand the serious health concerns that long COVID confronts us with, might have to do with certain evaluative decisions made early in the pandemic. During the first outbreak of COVID19 in spring 2020 the risk models focused on the mortality rate, the chance that IC-units would be full. Other risks were not taken into account and considered as mild COVID. Only when the 'mild' symptoms threaten to impact employability, long COVID becomes a topic of research and clinical guidelines. While it might seem very reasonable to focus first on the risk of death rather than the risk of lasting fatigue, the conceptual choice to keep long during effects out of the notion of COVID-19 and thus out of dedicated research programs and treatment trials has real consequences for many people. Biddle and Kukla make the case that these conceptual choices are driven by the interests of many stakeholders, and not only the interests of the most vulnerable parties namely the (potential) patients. With their characterisation of phronetic risks Biddle and Kukla want to underscore the influence of interests and values on scientific research. Combined with the lessons to be learned from standpoint epistemology, we think their work on epistemic risk urges for a diversification of interests and values in epistemic practices. A good way to do this is by diversifying the people that make the scientific choices and/or determine which scientific data are collected. This movement to standpoint epistemology as a scientific method would be conducive to solidarity. Let us illustrate this with the second case mentioned in "The Challenges of Pandemic Solidarity" section. When people with chronic illness or disabilities are given a voice in the scientific assessment of how constraining people find the lockdown measurement, a different, more nuanced and more truthful picture of the relation between COVID-19 and mental wellbeing would arise. This would make for better science in itself, we think, next to the fact that it would lead to better policy making. As standpoint epistemology and the standard of strong objectivity intends to show, there are not only many political and ethical, but also epistemological, reasons for including and empowering participation in health decision-making by those most significantly and directly affected by the policies in question. The ethical and political values at play here include harm, but also respect as in giving someone credibility as a knower. The epistemological value at play is inclusivity inspired by open-mindedness. What matters epistemologically speaking, is thus not so much that we should respect, let alone affirm everyone's opinion, but that we arrive at a better assessment of risks when we approach the possibilities of harm (i.e. the risks) from diverse perspectives.

In the production of scientific knowledge epistemic risks are taken. But also when communicating their research results to policy-makers scientists run risks, which we might call moral risks as policies may more or less harm people. Given the current state of scientific knowledge, and the great hopes we hold for scientific progress, it should not surprise nor worry us that politicians in contemporary western liberal democracies rely on scientists. Legal scholars have argued that in communication about measures to contain the pandemic, democratic leaders should always provide the scientific basis for their decisions such that citizens can play their role as critics [16]. Yet this does pose scientists for a challenge, as is explained by Roger Pielke 
in his book The Honest Broker. Making Sense of Science in Policy and Politics [15]. When they are asked for policy-advice, scientists can respond in a number of ways, identified by Pielke and distinguished on the basis of two parameters: whether there is consensus on the values in play, and whether there is scientific uncertainty. In situations where there is a broad consensus on values, like escaping an approaching tornado, reducing scientific uncertainty leads directly to a legitimate decision, and Pielke believes that in this scenario scientists may very well advice governments directly on what they should do. But not every case allows for what Pielke calls Tornado Politics. Whether legislation should allow for abortus at 18 weeks is a situation where the lack of consensus on values cannot be resolved by reducing scientific uncertainties. It would be naive, in the best case, or deceitful, in the worst, to think that science could prescribe the right political decision. COVID-19 Politics resembles what Pielke calls Abortion Politics, both in terms of the lack of consensus and the amount of scientific uncertainty. There are scientists who seek to reduce the range of options for politics by aligning themselves with the interests or values of a particular (political) group. Remember the (un)fairness argument of "The Challenges of Pandemic Solidarity" section. Youth counselors, student advocates and children psychologists urge politicians to prioritise the interests of children and young adults, by for example vaccinating the young before their parents. Or they urge the government to open university campuses on the basis of psychological data on students' wellbeing. Scientists can make this activist choice in good faith. There is nothing wrong with making the choice to be an Issue Advocate, says Pielke, as long as these scientists do not pretend that their preferred policies follow directly from scientific data and are not motivated by evaluative judgments. Of course, going back to our example, psychology is but one science and it would be wrong to deny the relevance of other data f.e. on the accessibility of online classes or on the impact of the use of public transport on transmission risks. An alternative to the Issue Advocate is the Honest Broker. Honest Brokers are scientists that seek to expand the range of policy options by adding even more options on the table. They identify all stakeholders and their concerns and try to align them with available scientific knowledge, clarifying which option would benefit which stakeholder and thus clarifying the trade-offs to be made by the politicians. Pielke remarks that Honest Brokers typically take the form of interdisciplinary advisory bodies rather than individual experts, as they have more perspectives to draw on. ${ }^{2}$ Thus, without calling it by name, Pielke makes a case for the integration of standpoint epistemology within scientific practices of advising policy makers, complementing the case that was made by Biddle and Kukla.

Diversification in the science community or the acquired scientific data will not solve the lack of consensus. It might even add to the variety of accounts available. The goal of diversification is not to decrease disagreement, which should never be a scientific goal in itself we think. The regulating ideal for scientists is truth, not

\footnotetext{
2 An additional advantage of collecting expertise in advisory boards (understandably not mentioned by Pielke who wrote the book in 2007) is that individual scientists do not stand out so much which protects them against social media disparagement or, sadly a reality, also in Belgium, death threats.
} 
consensus. Consensus might be a sign of truth being reached, but it need not be. Consensus can also signify the exclusion of dissident voices. Whether there may be reasons to exclude dissident voices, is a difficult question which needs more context than we can explore here. Surely the answer will take into account the scientific grounds that these dissident standpoints invoke. One perhaps paradoxical side effect of inclusive science that we see is that it may take the wind out of the sails of complot theorists. Complot theorists, like anti-vaxxers, project one so-called truth on the world and prefer their rigid theory to what they consider as the official story made up by science and politics. If scientific practice reflects the complexity of reality and hence the difficulty to reach certain knowledge and the need to be flexible rather than rigid, this might not lead to chaos but instead to less need for "alternative facts". We only mention this possibility as a bonus. Even if this specific beneficial result would not arise, the goal of standpoint theory was never to solve disagreement in society, nor scientific disagreement. The ideal of strong objectivity is rather meant to express epistemic doubts about agreement that is reached on pain of exclusion.

Diversifying the science upon which pandemic policy-making relies mitigates risks in at least two different senses. First by feeding different values and interests into the science design phronetic risks will be mitigated because they are wider informed, less exclusive. Second by diversifying the interests and values that determine the scientific question asked and the scientific research carried out, a more complex and multiperspectival view of so-called objective risks will emerge. For example, in such an approach, the ranking of 'objective risk' of transmission over the 'objective risk' of loneliness, social deprivation, family break ups, may appear artificial and tied to certain social positions, such as the well-privileged position of a middle class family with two children and employed parents. So both the risks inherent to science making (the phronetic risks) and the risks inherent to the pandemic as studied by science itself (the so-called objective risks) will be mitigated and managed better after incorporating the ideas of standpoint theory.

\section{Conclusion}

Ulrich Beck has argued that the Risk Society, with its indeterminate and sindividualised risks is not solely detrimental. It may also open up new understandings, new possibilities for different futures. Now that the COVID-19 pandemic has been going on for several months, it has become apparent that a mere technocratic approach to risk calculation is insufficient, and may even lack objectivity. For one, fighting a pandemic implies a call to solidarity, often on the basis of one simple metric ('transmission risk, fatality risk'). It has, however, become apparent that there is also uncertainty who we should be solidary with and why. Solidarity needs a solid ground. Appraising ideas from standpoint epistemology, also as part of the scientific method will allow for a more diverse conceptualisation, one we believe is also more objective. At the same time, insight in the different aspects and layers of the meaning of 'risk' may also give content to the duty to solidarity. It is beyond the scope of this paper to suggest how these ideas could be implemented. We think that research teams dealing with cosmopolitan risks such as (future) pandemics should 
be by definition interdisciplinary. It has been argued that those scientists who advise policy makers should be from different disciplines. But also the work that needs to be done beforehand, in the labs, can benefit from an interdisciplinary approach. A good way forward would be the implementation of methods from ethnographic fieldwork within scientific research groups. Ethnographers could investigate how epidemiological risk models are constituted and better understand the considerations involved in drafting and presenting an epidemiological risk model. But social scientists and philosophers can also bring to the table new viewpoints and angles. In this paper, we have used the examples of how the situatedness of persons with disabilities, persons grieving, or persons living in poverty may yield different insights for pandemic risk science. We should not stop there: we have written this paper from a Belgian perspective. As pandemics by their definition are worldwide, the Global North's pandemic science should question its own assumptions and incorporate ideas and knowledges from other cultures. A crisis is often a catalysator for social change. Therefore we hold the reasonable hope that the current pandemic harbours a change towards more inclusive democracy and more inclusive science. We believe that incorporating ideas from standpoint epistemology into science and ultimately policy making will help achieve that.

Funding Kristien Hens: This study was funded by European Research Council (Grant Number 804881).

\section{Declarations}

Conflict of interest The authors declare that they have no conflict of interest.

\section{References}

1. Beck, U., Lash, S., \& Wynne, B. (1992). Risk society: Towards a new modernity (Vol. 17). Sage.

2. Biddle, J. B., \& Kukla, R. (2017). The geography of epistemic risk. In K. C. Elliott \& T. Richards (Eds.), Exploring inductive risk: Case studies of values in science (pp. 215-235). Oxford University Press.

3. Bourgeois, L. (1902). Solidarité. A. Colin.

4. Chang, S., Pierson, E., Koh, P. W., Gerardin, J., Redbird, B., Grusky, D., \& Leskovec, J. (2021). Mobility network models of COVID-19 explain inequities and inform reopening. Nature, 589(7840), 82-87.

5. Fricker, M. (2009). Epistemic injustice: Power and the ethics of knowing. Oxford University Press.

6. Hacking, I. (2004). Historical ontology. Harvard University Press.

7. Hansson, S. O. (2018). Risk. In E. N. Zalta (Ed.), The Stanford Encyclopedia of Philosophy (Fall 2018 Ed.). https://plato.stanford.edu/archives/fall2018/entries/risk/

8. Harding, S. (1991). Whose science? Whose knowledge?: Thinking from women's lives. Cornell University Press.

9. Harding, S. (2004). Rethinking standpoint epistemology: What is "strong objectivity?" In S. Harding (Ed.), The feminist standpoint theory reader (pp. 127-140). Routledge.

10. Harding, S. (2020). The myth of pure science. Retrieved July 18, 2021, from https://iai.tv/articles/ the-myth-of-pure-science-auid-1682

11. Het huidige coronabeleid moet omgegooid worden. (2020). Retrieved July 18, 2021, from https:// www.tijd.be/opinie/algemeen/het-huidige-coronabeleid-moet-omgegooid-worden/10247504.html

12. Nussbaum, M. C. (2015). Political emotions. Belknap Press. 
13. Pascoe, J., \& Stripling, M. (2020). Surging solidarity: Reorienting ethics for pandemics. Kennedy Institute of Ethics Journal, 30(3), 419-444.

14. Perez, C. C. (2019). Invisible women: Exposing data bias in a world designed for men. Random House.

15. Pielke, R. A., Jr. (2007). Making sense of science in policy and politics. Cambridge University Press.

16. Popelier, P., Kleizen, B., Declerck, C., Glavina, M., \& Van Dooren, W. (2021). Covid-19 en exitmaatregelen: Een surveyexperiment over de percepties van burgers over overheidsmaatregelen na de piek van de eerste Covid-19 golf. GOVTRUST Onderzoeksexcellentieconsortium, Universiteit Antwerpen. Retrieved 2/5//2021, from https://www.uantwerpen.be/en/research-groups/govtrust/ research/projects/bof-covid19/report1/

17. Prainsack, B. (2020). Solidarity in times of pandemics. Democratic theory, 7(2), 124-133.

18. Prainsack, B., \& Buyx, A. (2011). Solidarity: Reflections on an emerging concept in bioethics. Nuffield Council on Bioethics.

19. Roeser, S. (2017). Risk, technology, and moral emotions. Routledge.

20. Rorty, R. (1989). Contingency, irony, and solidarity. Cambridge University Press.

21. The Lancet. (2020). Facing up to long COVID. The Lancet, 396(10266), 1861.

22. West-Oram, P. G. N., \& Buyx, A. (2017). Global health solidarity. Public Health Ethics, 10(2), 212-224.

23. Williams, P. J., Lewis, M., \& Durant, D. (2021). Maybe we shouldn't go back to normal. The Nation. Retrieved from https:/www.thenation.com/article/society/covid-back-to-normal/

Publisher's Note Springer Nature remains neutral with regard to jurisdictional claims in published maps and institutional affiliations. 